\title{
Effect of Eccentric and Concentric Contraction Mode on Myogenic Regulatory Factors Expression in Human Vastus Lateralis Muscle
}

Mostafa Sabouri ( $\square$ mostafasaboory@ut.ac.ir)

Payame Noor University https://orcid.org/0000-0001-5088-7955

Pejman Taghibeikzadehbadr

Tehran University: University of Tehran

Fatemeh Shabkhiz

Tehran University: University of Tehran

Zahra Izanloo

University of Bojnord

Farahnaz Amir Shaghaghi

Tehran University: University of Tehran

\section{Research}

Keywords: Eccentric contraction, Concentric contraction, Gene expression, Myogenic regulatory factors

Posted Date: September 22nd, 2021

DOl: https://doi.org/10.21203/rs.3.rs-800966/v1

License: (c) (i) This work is licensed under a Creative Commons Attribution 4.0 International License. Read Full License

Version of Record: A version of this preprint was published at Journal of Muscle Research and Cell Motility on January 12th, 2022. See the published version at https://doi.org/10.1007/s10974-021-09613$\mathrm{X}$. 


\section{Abstract}

Background: Skeletal muscle contractions are caused to release myokines by muscle fiber. This study investigated the myogenic regulatory factors, as MHC I, IIA, IIX, Myo-D, MRF4, Murf, Atrogin-1, Decorin, Myonection, and IL-15 mRNA expression in the response of eccentric vs. concentric contraction.

Methods: Eighteen healthy men were randomly divided into two eccentric and concentric groups, each of 9 persons. Isokinetic contraction protocols included maximal single-leg eccentric or concentric knee extension tasks at $60 \%$ s with the dominant leg. Contractions consisted of a maximum of 12 sets of 10 reps, and the rest time between each set was 30 seconds. The baseline biopsy was performed four weeks before the study, and post-test biopsies were taken immediately after exercise protocols from Vastus Lateralis muscle. The gene expression levels evaluated using Real-Time PCR methods.

Results: A significant difference in MyoD, MRF4, Myonection, and Decorin mRNA, were observed following eccentric or concentric contractions (P $\leq 0.05)$. The MHC I, MHC IIA, IL-15 mRNA has been changed significantly compared to the pre-exercise in the concentric group $(P \leq 0.05)$. While only MHC IIX and Atrogin-1 mRNA changed significantly in the eccentric group $(P \leq 0.05)$. Additionally, the results showed a significant difference in MyoD, MRF4, IL-15, and Decorin were observed at the follow-up values between eccentric or concentric groups $(P \leq 0.05)$.

Conclusion: Our findings highlight the growing importance of elucidating the different responses of muscle growth factors associated with a myogenic activity such as MHC IIA, Decorin, IL-15, Myonectin, Decorin, MuRF1, and MHC IIX mRNA in following to various types of exercise.

\section{Background}

Skeletal muscle is a high adaptable and malleable tissue that participating in voluntary contraction according to command and responds to environmental and physiological challenges $(1,2)$. Increasing data suggest that skeletal muscle in response to exercise training synthesizes a range of secreted factors, known as myokines, that may play a significant role in muscle development and regeneration $(3,4)$. In this regard, previous research has established functions of myogenic regulatory factors (MRFs) to differentiate and grow muscle $(5,6)$. MRFs (Myo-D, myogenin, MRF-4, MYF-5) have a significant role in synthesizing muscle protein through sarcomeric factors such as tropomyosin, troponin-c, myosin heavy and light chains (7). Previously studies found that stretching stimulation induced the myocyte growth and differentiation and changed muscle of myosin heavy chains (MHC) isoforms level $(8,9)$. Also, MRF-4, Myo-D, and myogenin genes were substantially increased following a single resistance exercise $(10,11)$. Therefore, it indicates that the MRFs family are susceptible to single bouts resistance training and could be implicated in myogenesis and hypertrophy's modulation.

Nevertheless, several experiments have found no impact on MYF-5 (11) and MRF-4 (12) mRNA in the response of resistance exercise. In comparison, skeletal muscle protein synthesis is mostly related to the myosin contractile protein (13). In this regard, $\mathrm{MHC}$ isoforms are the most abundant muscle protein, 
making MHC an essential modulator of muscle fiber's functional diversity (10). In animals and humans, intense resistance exercise improved the $\mathrm{MHC}$ isoforms mRNA $(10,14,15)$. Consequently, it seems that muscle contraction intensity has a remarkable role in $\mathrm{MHC}$ expression. It has been shown that during differentiation of myoblast, IL-15 mRNA expression is increased (2). Several studies found that exercise training could be aggregated IL-15 in skeletal muscles $(16,17)$. Besides, in skeletal muscles, IL-15 has anabolic effects by increasing insulin sensitivity $(18,19)$. However, chronic injection of IL-15 causes atrophy $(20)$ and hypertrophy in animals model $(21,22)$. Myonectin is another myokine released into the bloodstream through muscle contraction and facilitates the uptake of fatty acids into cells through enhanced fatty acid transfer genes $(23,24)$. Accordingly, the expression of myonectin is upregulated by voluntary exercise in the muscles and blood (24). Hence, myonectin can improve muscle mass through the increase and decrease protein synthesis and protein breakdown, respectively. Decorin, identified as a myokine, plays critical roles in the cell-matrix crosstalk modulation $(25,26)$. Moreover, hypertrophy of muscle fibers is promoted by Decorin through prohibiting myostatin (27-29). Although overexpression of decorin enhances the expression of MyoD and follistatin, it reduces MuRF1 (muscle ring finger-1) and atrogin-1 (30). Resistance training has already been shown to enhance the systematic appearance of decoration $(29,31)$.

On the other hand, skeletal muscle protein balance is controlled by both breakdown and synthesis of muscle protein $(32,33)$. The special muscle protein ligases, atrogin-1 and MuRF1, were considered proteolysis enzymes for ubiquitin-mediated $(34,35)$ that were considerably increased by forkhead transcription factors (FoXO) (11). In this regard, the lack of Atrogin-1 and MuRF1 inhibits muscle atrophy in mice $(36,37)$, are identified as primary mediators of degradation and atrophy muscle protein (38). Similarly, MuRF1 and atrogin-1 mRNA are improved by resistance exercise that induced muscle hypertrophy (39). Besides, the mode of exercise contraction regulated the MuRF1 and atrogin-1 values differently. In that way, after single-bout of eccentric and concentric contraction, the mRNA level of atrogin-1 expression is de-regulated $3-12 \mathrm{~h}$ after exercise (40-42), whereas increasing of MuRF1 levels have been found $1-4 \mathrm{~h}$ after exercise (41-43). In another study, atrogin-1 downregulation and MuRF1upregulation have been shown by isolated eccentric and concentric contraction, respectively $(44,45)$.

Concentric contraction involves the dynamic shortening of sarcomeres, while eccentric contraction involves the lengthening of sarcomeres (46). There is some evidence that eccentric contraction produces significantly muscle force, neuromuscular adaptations, increased anabolic signaling and gene expression, and a more rapid protein synthetic response than concentric contraction (47-50). Nevertheless, some studies $(46,51,52)$ have indicated the same increases in strength and muscle hypertrophy after eccentric and concentric contraction, specifically in similar intensity or volume of exercises. Given the gaps in our knowledge base, the different effects of eccentric and concentric contraction on hypertrophy and strength gains are controversial. From all the above, it can be conducted that the signaling pathways of these two contractions are likely to result in structural, physiological, and molecular differences in skeletal muscle (53). Hence, the response of MHC I, IIA, IIX, Myo-D, MRF4, Murf, 
Atrogin-1, Decorin, Myonection, and IL-15 mRNA expression has been investigated following eccentric and concentric exercise in human vastus lateralis muscle.

\section{Materials And Procedure}

\subsection{Participants}

Eighteen healthy men were recruited to this study and randomly divided into eccentric $(n=9)$ and concentric $(n=9)$ groups. The experimental protocol consisted of two sessions (familiarization and isokinetic test) described below. Subjects were not involved in resistance training and lower body musculoskeletal conditions for at least six months before beginning the study. All procedures were approved by the University of Tehran ethical committee (Ethic No: IR.UT.SPORT.REC.1397.029).

Table 1

Anthropometric characteristics of participants in two groups

\begin{tabular}{|lll|}
\hline Variables & Concentric & Eccentric \\
\hline Age $($ Year $)$ & $27.25 \pm 2.78$ & $25.65 \pm 3.74$ \\
\hline Height $(\mathrm{Cm})$ & $175.88 \pm 4.64$ & $176.44 \pm 5.57$ \\
\hline Weight $(\mathrm{Kg})$ & $74.44 \pm 3.04$ & $70.22 \pm 2.81$ \\
\hline$\left(\mathrm{BMI}\left(\mathrm{kg} / \mathrm{m}^{2}\right)\right.$ & $24.12 \pm 1.58$ & $22.57 \pm 1.58$ \\
\hline
\end{tabular}

\subsection{Familiarization}

A week before each resistance exercise, the knee extension Maximal Voluntary Isometric Action (MVIA) of the dominant leg was determined using a standard dynamometer (Biodex, Shirley, NY USA). Leg dominance was identified by asking the individuals the preferred leg to kick a ball (54). Before testing the MVIA all subjects performed a general warm-up consisting of 10-minute cycling without load at the range of 60-80 rpm on the stationary cycle before the MVIA test. Subsequently, each participant underwent a brief familiarization with the isokinetic dynamometer, involving $5-10$ submaximal contractions ( $25 \%$ of MVIA) with the dominant leg.

For MVIA, the knee was positioned at a 60-degree knee extension (full extension $-0^{\circ}$ ). Three trials $(5 \mathrm{~s}$ for each trial) were conducted, with intervals of $3 \mathrm{~min}$ between them. Additional trials were conducted if the participants did not achieve at least two trials with similar results. Participants were strongly encouraged during the task. 
After MVIA tests, individuals were familiarized with the maximal eccentric and concentric leg extension force was measured. Following a five-minute warm-up on a cycle ergometer, participants received detailed instructions on the eccentric and concentric leg extension exercises, and performed 10 repetitions of each exercise at maximal effort. The maximum force of the knee extensors for eccentric and concentric leg extension was performed with the dominant leg at $60 \%$ s.

\subsection{Isokinetic test}

The experimental protocol was conducted in a separate day ( 7 days apart from the familiarization session). Before the isokinetic test each individual performed a general warm-up consisting of five-minute cycling without load, and a specific warm-up using the Biodex isokinetic device at $25 \%$ of MVIA (5 concentric or eccentric contractions, according to the group randomization, with an intervals of 30 seconds between each set). The participants then performed one of the isokinetic protocols below with the dominant leg.

Eccentric protocol: Each contraction was performed at $60 \%$ s. Individuals performed 12 sets of 10 repetitions with 30 seconds of rest between each set, for a total of 120 contractions. Movement at the shoulders, hips, and thigh (exercised leg) were restrained with straps to isolate the knee extensors during the protocols and secure the participant to the device. The eccentric contraction was performed at $>90 \%$ of maximal load eccentric strength and the concentric component was passive (i.e. investigator moved the limb back to the starting position). Visual feedback of the force signal was provided to each individual. Participants were verbally encouraged to maintain the contraction levels during the task. At the end of each set, the rating of perceived exertion (RPE) was determined using the 20-point scale. One participant was not able to maintain the intensity level during the whole task and performed only 10 sets.

Concentric protocol: The protocol was similar to the eccentric one but the individuals performed concentric contractions at $90 \%$ of their maximal instead of eccentric ones. The eccentric portion of the movement was passive (i.e. the investigator returned the limb to initial position). Visual feedback was also provided and individuals reported their RPE between sets. The full concentric protocol was performed by all participants.

\subsection{Muscle Biopsy}

Two samples were collected: 1) four weeks before the eccentric/concentric protocol and 2) immediately after the concentric/eccentric protocol. Tissue biopsies were collected from the mid-portion of the Vastus Lateralis muscle in the morning (11-12 am). The area was locally anesthetized ( $0.1 \mathrm{ml}$ of lidocaine), and a Bergström needle was used. The samples were cleaned from blood and connective tissue, then frozen immediately in liquid nitrogen and stored at $-80^{\circ} \mathrm{C}$ until gene expression analysis. 


\subsection{Gene expression}

Expression of Myosin Heavy Chain (MHC) I, IIA, IIX, Myo-D, MRF4, Murf, Atrogin-1, Decorin, Myonection, and IL-15 was identified with real-time Polymerase Chain Reaction (PCR). Total RNA was extracted based on the Cinna Gen protocol using kiazol solution (Cinnacolon, Iran). To ensure no contamination with genomic DNA, the samples were first exposed to DNAse (DNase I Fermentas). The quality of extracted RNAs was evaluated with a spectrophotometric device (DPI-1, Kiagen). For reverse-transcribed of RNAs to cDNA used Strand cDNA Synthesis Kit (Oligo dt MWG-Biotech, Germany). The PCR reaction was conducted using the PCR master mix (Applied Biosystems) and Syber Green in the ABI Step One (Applied Biosystems, Sequences Detection Systems, Foster City, CA). For each Real-Time PCR cycle, a total of 40 cycles were considered, and the temperatures for each cycle were set at $94^{\circ} \mathrm{C}$ for $20 \mathrm{~s}, 60-58^{\circ} \mathrm{C}$ for the $30 \mathrm{~s}$, and $72^{\circ} \mathrm{C}$ for $30 \mathrm{~s}$, respectively. The primer sequence is shown in Table.2. The expression of GAPDH confirmed that PCR conditions were optimized. Melting diagrams were performed to check the accuracy of PCR reactions. They were evaluated for each gene individually and at each reaction time, along with negative control diagrams to check for contamination in each reaction. Relative expression of the gene was analyzed using Prism software after manually setting the baseline and threshold. The RT-PCR data were analyzed using the delta-delta cycle threshold (DDCt) method. All Real-time PCR procedures were performed in triplicate.

Table 2

Target genes and sequence of primers 


\begin{tabular}{|c|c|c|}
\hline Gene & Forward/Reverse & Primer $\left(5^{\prime} \rightarrow 3^{\prime}\right)$ \\
\hline \multirow[t]{2}{*}{ MyoD } & $\mathrm{F}$ & GGTGGGGGATAGTGGGTGGG \\
\hline & $\mathrm{R}$ & TGTGGCAAAGGAGGAGAGAGAG \\
\hline \multirow[t]{2}{*}{ MRF4 } & $\mathrm{F}$ & GATAACGGGTAAGGAAGGAGGAG \\
\hline & $\mathrm{R}$ & AAGGATTAGGTCAGGAAGGGT \\
\hline \multirow[t]{2}{*}{ IL-15 } & $\mathrm{F}$ & GGAGGTATTGTGGATGGATGG \\
\hline & $\mathrm{R}$ & ACAGAAGTAGCACTGGATGGA \\
\hline \multirow[t]{2}{*}{ Myonectin } & $\mathrm{F}$ & AGGTGGTGGATGAGAGATGGT \\
\hline & $\mathrm{R}$ & TACTGTGGGGAAAATGTGGGA \\
\hline \multirow[t]{2}{*}{ Decorin } & $\mathrm{F}$ & TGAAGGGAGAAGACATTGG \\
\hline & $\mathrm{R}$ & GGAAGATAGGGAGAGGTAGA \\
\hline \multirow[t]{2}{*}{ MHC I } & $\mathrm{F}$ & CATTGAGGAGCTGGAGGAGGA \\
\hline & $\mathrm{R}$ & TGGCTTCATGCTGTAGGGTGG \\
\hline \multirow[t]{2}{*}{ MHC ॥A } & $\mathrm{F}$ & AGCAGAGAAGGAGGAAAAGTGA \\
\hline & $\mathrm{R}$ & CACTTGTAGGGGTTGACAGTGA \\
\hline \multirow[t]{2}{*}{ MHC IIX } & $\mathrm{F}$ & GCAGGAGGAGTACAAGAAGGAA \\
\hline & $\mathrm{R}$ & TTGGGGTTCTGGAAGTTGTTGG \\
\hline \multirow[t]{2}{*}{ Atrogin-1 } & $\mathrm{F}$ & АСТССАСАСССТСТАСАСАТСС \\
\hline & $\mathrm{R}$ & ТСТССАТСССАТАСАСССАСА \\
\hline \multirow[t]{2}{*}{ MuRF-1 } & $\mathrm{F}$ & TGTCCAGACCATCATCACTCA \\
\hline & $\mathrm{R}$ & ААСТСАСТТСТСТТСТСАТССА \\
\hline \multirow[t]{2}{*}{ GAPDH } & $\mathrm{F}$ & GCA GGG ATG ATGTTC TGG \\
\hline & $\mathrm{R}$ & CTT TGG TAT CGT GGA AGG AC \\
\hline
\end{tabular}

\subsection{Statistical Analysis}

Statistical analysis was conducted using SPSS software (version 21; IBM, Chicago, IL) and reported as mean \pm SD. The normality of the data and equality of variances were tested using the Shapiro-Wilk and Levine test, respectively. Mixed-design repeated measures analysis of variance (ANOVA) was run to 
analyses differences across time (baseline vs. follow-up) and groups (eccentric vs. concentric) in all variables (Myo-D, MRF4, IL-15, Myonection, Decorin, MHC I, IIA, IIX, Atrogin-1, and Murf mRNA expression). Where an interaction effect was observed, independent samples $t$ test was performed to compare variables at baseline and follow-up change between eccentric and concentric groups. In addition, changes over time (baseline vs. follow-up) in each group were assessed using paired t-test. Partial eta squared effect size was reported for group xtime interaction. For all statistical analyses an alpha of $\mathrm{p} \leq 0.05$ was considered statistically significant for all comparisons.

\section{Result}

\section{MyoD}

A two-way mixed ANOVA with repeated measures showed that there were statistically significant interaction effects (group $\times$ time) for $\operatorname{MyoD}\left(F_{(1.16)}=9.396, P=0.007, n p 2=0.369\right)$. According to the follow-up tests, significant differences in MyoD were observed at the follow-up values between CON and ECC groups $(P=0.004)$. Moreover, the paired t-test results showed that compared to the baseline level, MyoD significantly increased in both CON and ECC group ( $P \leq 0.05$, Fig $1 A)$.

\section{MRF4}

The results showed that there were statistically significant interaction effects (group $\times$ time) for MRF4 ( $F$ $\left.(1.16)=10.005, P=0.006, \mathrm{np}_{2}=0.385\right)$. According to the follow-up tests, significant differences in MRF4 were observed at the follow-up values between CON and ECC groups $(P=0.005)$. Moreover, the paired $t-$ test results showed that compared to the baseline level, MRF4 significantly increased in both CON and ECC group ( $\mathrm{P} \leq 0.05$, Fig 1B).

\section{IL-15}

A two-way mixed ANOVA with repeated measures showed that there were no statistically significant interaction effects (group $\times$ time) for IL-15 $\left(F_{(1.16)}=3.679, P=0.073, n p 2=0.187\right)$. However, the main effect of time showed a statistically significant increase in IL-15 from baseline to follow-up ( $P \leq 0.05)$ in CON group. Moreover, there was a significant difference in IL-15 at the follow-up values between CON and ECC groups $(P=0.024$, Fig $1 C)$.

\section{Myonection}

A two-way mixed ANOVA with repeated measures showed that there were no statistically significant interaction effects (group $\times$ time) for Myonection $\left(F_{(1.16)}=2.315, P=0.148, \eta p 2=0.126\right)$. However, the main effect of time showed a statistically significant increase in Myonection from baseline to follow-up 
$(\mathrm{P} \leq 0.05)$ in both CON and ECC groups. Moreover, there was no significant difference in Myonection at the follow-up values between CON and ECC groups ( $P=0.102$, Fig 1D).

\section{Decorin}

A two-way mixed ANOVA with repeated measures showed that there were statistically significant interaction effects (group $\times$ time) for Decorin $\left(F_{(1.16)}=16.062, P=0.001, \eta p 2=0.501\right)$. According to the follow-up tests, significant differences in Decorin were observed at the baseline and follow-up values between CON and ECC groups $(P \leq 0.05)$. Moreover, the paired t-test results showed that compared to the baseline level, Decorin significantly increased in both CON and ECC group ( $P \leq 0.05$, Fig 2A).

\section{MHC I}

A two-way mixed ANOVA with repeated measures showed that there were no statistically significant interaction effects (group $\times$ time) for $\mathrm{MHC} I\left(F_{(1.16)}=0.082, \mathrm{P}=0.778, \mathrm{np} 2=0.005\right)$. However, the main effect of time showed a statistically significant decrease in $\mathrm{MHC}$ I from baseline to follow-up in CON group $(\mathrm{P} \leq 0.05)$. Moreover, there was no significant difference in $\mathrm{MHC} I$ at the follow-up values between CON and ECC groups $(P=0.079$, Fig $2 B)$.

\section{MHC IIA}

The results showed that there were no statistically significant interaction effects (group $\times$ time) for MHC IIA $\left(F_{(1.16)}=2.130, P=0.164, n p 2=0.117\right)$. However, the main effect of time showed a statistically significant increase in MHC IIA from baseline to follow-up in CON group $(P \leq 0.05)$. Moreover, there was no significant difference in MHC IIA at the follow-up values between CON and ECC groups $(P=0.251$, Fig 2C).

\section{MHC IIX}

The results showed that there were no statistically significant interaction effects (group $\times$ time) for MHC $\| X\left(F_{(1.16)}=0.024, P=0.878, n p 2=0.002\right)$. However, the main effect of time showed a statistically significant increase in MHC IIX from baseline to follow-up in ECC group ( $\mathrm{P} \leq 0.05)$. Moreover, there was no significant difference in MHC IIX at the follow-up values between CON and ECC groups $(P=0.537$, Fig 2D).

\section{Atrogin-1}


A two-way mixed ANOVA with repeated measures showed that there were statistically significant interaction effects (group $\times$ time) for Atrogin-1 $\left(F_{(1.16)}=7.159, P=0.017, n p 2=0.309\right)$. The paired t-test results showed that compared to the baseline level, Atrogin-1 significantly decreased in ECC group ( $P \leq$ 0.05). Moreover, there was no significant difference in Atrogin-1 at the follow-up values between $C O N$ and ECC groups $(P=0.601$, Fig $3 A)$.

\section{MuRF1}

The results showed that there were no statistically significant interaction effects (group $\times$ time) for MuRF1 $\left(F_{(1.16)}=3.954, P=0.064, \eta p 2=0.198\right)$. Moreover, there was no significant main effect of time $(P$ $=0.971$, Fig 2B).

\section{Discussion}

This study investigates the effects of two types of contractions on gene expression of myogenesis factor, including muscle hypertrophy. The results showed a significant difference in MyoD, MRF4, IL-15, and Decorin were observed at the follow-up values between CON and ECC groups $(P \leq 0.05)$. Moreover, the results showed that compared to the baseline level, MyoD, MRF4, Myonection, and Decorin significantly increased in both CON and ECC group ( $\mathrm{P} \leq 0.05)$. MHC I, MHC IIA, IL-15 showed a statistically significant

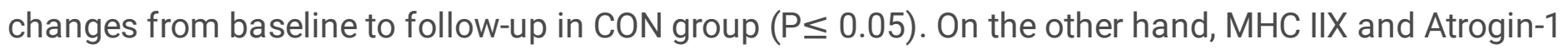
showed a statistically significant changes from baseline to follow-up in ECC group $(P \leq 0.05)$.

The results have been shown expression of MHC IIA and MHC I mRNA significantly changed in the CON group, while MHC IIX significantly increased in the ECC group. In this regard, previously demonstrated that the expression of $\mathrm{MHC} \mathrm{I,} \mathrm{MHC} \mathrm{IIA,} \mathrm{and} \mathrm{MHC} \mathrm{IIX} \mathrm{increased} \mathrm{in} \mathrm{the} \mathrm{response} \mathrm{of} \mathrm{a} \mathrm{single} \mathrm{high} \mathrm{intensity}$ resistance training $(10,14)$. Moreover, remobilization of the soleus muscle in the flat treadmill induced an increases of $\mathrm{MHC}$ I content, while eccentric training did not show significant changes in the content of this type of MHC protein (55). Hence, muscle contraction tends to be a modulator of MHC isoforms, despite the type of contraction. Several factors have now been identified, which stimulate an increase in muscle volume after mechanical loading $(56,57)$. It has been found that some of these effectors affect myoblast hypertrophy $(5,6)$. In line with previous researches, we have demonstrated that ECC and CON muscle contraction is adequate for the upregulation of Myo-D, MRF-4 and myonectin mRNA levels in the VL muscle. Previous research showed a significant increase only in MRF-4 in the eccentric group $(58,59)$. Psilander et al. found a single heavy-resistance exercise bout considerably upregulated expression of Myo-D and MRF-4 mRNA (60). The importance of these findings is that the Myo-D and MRF-4 probably have the primary role in controlling $\mathrm{MHC}$ genes. Previous researches have represented that the expression of Myo-D and myogenin are related to alterations of isoform composition of MHC comparing to muscle mass $(14,61)$. Moreover, myonectin, a novel myokine, affects fat metabolism and reduces the amount of circulating lipids (24). Seldin et al. represented that voluntary exercise by wheel running increased the expression of the myonectin gene (24). Pourranjbar et al. have shown that engaging in 
aerobic training increased significantly myonectin in obese women (62). Also, myonectin has been demonstrated to promote the uptake of fatty acids in cultured adipocytes and hepatocytes and suppress the circulating of free fatty acid levels in mice (63); furthermore, the erythroid modulator of iron metabolism and hemoglobin synthesis $(64,65)$.

Moreover, in present work, CON and ECC exercise increased IL-15 mRNA expression in the VL muscle, and there was a significant difference between CON and ECC in IL-15 follow-up values. In that way, the IL-15 increased significantly after a single leg maximal isokinetic eccentric resistance exercise (66).

Furthermore, Bazgir et al. have shown that ECC and CON resistance exercise considerably increased IL-15 serum in non-athlete individuals (67). As well as, the resistance exercise could induce the increase of IL15 mRNA in the vastus lateralis muscle (68). As a consequence, improvements of IL-15 mRNA expression will be predicted after resistance exercise training. Quinn et al. indicated the increase and decrease in IL-15 mRNA levels in muscle and circulation, respectively, the sequence of a single bout of running exercise in the animal model (69). It seems that contraction-induced muscle tissue secretion of IL-15 might lead to these differences. It must be indicated that the type of skeletal fiber, intensity, volume of training, and metabolic status could affect alteration of IL- 15 mRNA after exercise (3).

Furthermore, the results reported that a single bout of CON and ECC contraction changed the decorin mRNA level in VL muscle. Simultaneously, the results have shown a significant difference in decorin mRNA expression in the follow-up measures between two groups. In this regard, a single bout of endurance activity could increase the decorin mRNA in skeletal muscle (70). Decorin has been shown to improve the response of an acute resistance exercise bout; however, it returns to the baseline level after an hour of exercise (29). The most important result of this study is that concentric muscle contraction produced more decorin mRNA expression immediately post-exercise. Moreover, there were significant differences between the ECC and CON contraction in Decorin, which indicate that Decorin might be a distinguishing factor between the hypertrophic responses (71).

Atrogin-1 and MuRF1 are present in the degradation of muscle proteins and are assumed to have a significant role in muscle atrophy in disease conditions $(36,37)$. Resistance training, known as a positive modulator of muscle health, controlled the levels of MuRF1 and atrogin-1 mRNA, while the mode of contraction and type of exercise might play a significant role (72). To clear the effect of type of contraction on these targets of atrophy, isolated ECC and CON contraction were used in this study. The results showed that Atrogin-1 mRNA expression was sensitive to single-bout muscle contraction in a contraction mode-dependent manner. Atrogin-1 mRNA levels decreased significantly in ECC group. In this regard, ECC contraction downregulated expression of MuRF1 and Atrogin-1 mRNA, while CON exercise produced a consistent upregulation of FOXO1 and MURF1, under the same contraction times $(44,72)$. Atrogin-1 was attenuated after the ECC-exercised muscle, in which CON contractions have not considerable effect (45). In another study, Coffey et al. indicated that Atrogin-1 mRNA levels tend to reduce following a single endurance exercise bout, while there was no significant alteration in strength athletes (40). 
Moreover, in line with previous researches increasing MuRF-1 mRNA has been presented in this study $(73,74)$. In contrast, a study conducted by Churchley et al. showed a decrease in MuRF mRNA following an acute resistance training bout (75). It seems that different behavior of the Atrogin-1 and MuRF in the response of resistance training may suggest that they have different roles in the proteolysis process. Moreover, it would be possible that a single bout of resistance training could trigger adequate muscle damage and activated these negative regulators of muscle growth $(41,72)$.

There have been some possible limitations in this research, which must be considered in the next researches. The sample limitation of muscle biopsy might have a tangible effect on results due to transient response. For future research, this possibility can be discussed by thought increasing sample research. Besides, it must be mentioned that results taken as a consequence are focused on alterations in mRNA, while protein changes remain unclear in current work.

\section{Conclusion}

This study investigated the single bout of isolated ECC and CON contraction on several of myogenic regulatory factors. Our results showed that muscle contraction has variable effects on mRNA expression of MyoD, MRF4, IL-15, and Decorin, IL-15 and MHC isoforms. Moreover, Atrogin-1, which is known as negative regulator of muscle growth, showed different alterations following ECC and CON contraction. Therefore, it provides a new vision into how the type of contraction in resistance exercise influences myogenic factors.

\section{Abbreviations}




\begin{tabular}{|ll|}
\hline Abbreviations/Codes & \\
\hline MHC & Myosin heavy chains \\
\hline Myo-D & Myoblast determination protein 1 \\
\hline MRF4 & Myogenic regulatory factor 4 \\
\hline Murf & Muscle ring finger-1 \\
\hline IL-15 & Interlukin-15 \\
\hline MRFs & Myogenic regulatory factors \\
\hline MYF-5 & Myogenic factor 5 \\
\hline mRNA & Messenger ribonucleic acid \\
\hline FoXO & Forkhead transcription factors \\
\hline MVIA & Maximal Voluntary Isometric Action \\
\hline CO & Concentric \\
\hline ECC & Eccentric \\
\hline
\end{tabular}

\section{Declarations}

\section{Ethical approval:}

All procedures performed in studies involving human participants were by the ethical standards of the ethical committee of Tehran University (Ethic No: IR.UT.SPORT.REC.1397.029) and with the 1964 Helsinki declaration and its later amendments or comparable ethical standards.

\section{Consent to Participate:}

Informed consent was obtained from all individual participants included in the study. Participants signed informed consent regarding publishing their data and photographs.

\section{Availability of data and materials:}

The datasets used and/or analyzed during the current study are available from the corresponding author on reasonable request.

\section{Funding:}




\section{Competing interest:}

The authors declare no conflict of interest.

\section{Author Contribution:}

MS, PT, FS designed the study. ZI, MS, and FA collected the data. FA and MS revised the final version of the manuscript. All authors read and approved the manuscript.

\section{Acknowledgments:}

We would like to thank the nurses and personnel of the University of Tehran and the Faculty of Medical Sciences to help with the clinical portion of this study.

\section{References}

1. Frontera WR, Ochala J. Skeletal muscle: a brief review of structure and function. Calcif Tissue Int. 2015;96(3):183-95.

2. Lee JH, Jun HS. Role of Myokines in Regulating Skeletal Muscle Mass and Function. Frontiers in physiology. 2019;10:42.

3. Molanouri Shamsi M, Hassan ZM, Quinn LS, Gharakhanlou R, Baghersad L, Mahdavi M. Time course of IL-15 expression after acute resistance exercise in trained rats: effect of diabetes and skeletal muscle phenotype. Endocrine. 2015;49(2):396-403.

4. Henriksen T, Green C, Pedersen BK. Myokines in myogenesis and health. Recent Patents Biotechnol. 2012;6(3):167-71.

5. Wei Q, Paterson BM. Regulation of MyoD function in the dividing myoblast. FEBS Lett. 2001;490(3):171-8.

6. Berkes CA, Tapscott SJ. MyoD and the transcriptional control of myogenesis. Semin Cell Dev Biol. 2005;16(4-5):585-95.

7. Bergstrom DA, Penn BH, Strand A, Perry RL, Rudnicki MA, Tapscott SJ. Promoter-specific regulation of MyoD binding and signal transduction cooperate to pattern gene expression. Mol Cell. 2002;9(3):587-600.

8. Sakiyama K, Abe S, Tamatsu Y, Ide Y. Effects of stretching stress on the muscle contraction proteins of skeletal muscle myoblasts. Biomedical research. 2005;26(2):61-8.

9. Kurokawa K, Abe S, Sakiyama K, Takeda T, Ide Y, Ishigami K. Effects of stretching stimulation with different rates on the expression of MyHC mRNA in mouse cultured myoblasts. Biomedical research. 
2007;28(1):25-31.

10. Wilborn CD, Taylor LW, Greenwood M, Kreider RB, Willoughby DS. Effects of different intensities of resistance exercise on regulators of myogenesis. Journal of strength conditioning research. 2009;23(8):2179-87.

11. Yang $Y$, Creer A, Jemiolo B, Trappe S. Time course of myogenic and metabolic gene expression in response to acute exercise in human skeletal muscle. J Appl Physiol. 2005;98(5):1745-52.

12. Kim J-s, Kosek DJ, Petrella JK, Cross JM, Bamman MM. Resting and load-induced levels of myogenic gene transcripts differ between older adults with demonstrable sarcopenia and young men and women. J Appl Physiol. 2005;99(6):2149-58.

13. McCall GE, Byrnes WC, Fleck SJ, Dickinson A, Kraemer WJ. Acute and chronic hormonal responses to resistance training designed to promote muscle hypertrophy. Canadian journal of applied physiology = Revue canadienne de physiologie appliquee. 1999;24(1):96-107.

14. Willoughby DS, Nelson MJ. Myosin heavy-chain mRNA expression after a single session of heavyresistance exercise. Med Sci sports Exerc. 2002;34(8):1262-9.

15. Caiozzo VJ, Haddad F, Baker MJ, Baldwin KM. Influence of mechanical loading on myosin heavychain protein and mRNA isoform expression. J Appl Physiol. 1996;80(5):1503-12.

16. Tamura Y, Watanabe K, Kantani T, Hayashi J, Ishida N, Kaneki M. Upregulation of circulating IL-15 by treadmill running in healthy individuals: is IL-15 an endocrine mediator of the beneficial effects of endurance exercise? Endocrine journal. 2011;58(3):211-5.

17. Brunelli DT, Chacon-Mikahil MP, Gaspari AF, Lopes WA, Bonganha V, Bonfante IL, et al. Combined Training Reduces Subclinical Inflammation in Obese Middle-Age Men. Med Sci sports Exerc. 2015;47(10):2207-15.

18. Barra NG, Chew MV, Holloway AC, Ashkar AA. Interleukin-15 treatment improves glucose homeostasis and insulin sensitivity in obese mice. Diabetes Obes Metab. 2012;14(2):190-3.

19. Quinn LS, Anderson BG, Conner JD, Pistilli EE, Wolden-Hanson T. Overexpression of interleukin-15 in mice promotes resistance to diet-induced obesity, increased insulin sensitivity, and markers of oxidative skeletal muscle metabolism. International journal of interferon cytokine mediator research. 2011;3:29-42.

20. Pistilli EE, Alway SE. Systemic elevation of interleukin-15 in vivo promotes apoptosis in skeletal muscles of young adult and aged rats. Biochem Biophys Res Commun. 2008;373(1):20-4.

21. Quinn LS, Haugk KL, Grabstein KH. Interleukin-15: a novel anabolic cytokine for skeletal muscle. Endocrinology. 1995;136(8):3669-72.

22. Quinn LS, Anderson BG, Drivdahl RH, Alvarez B, Argiles JM. Overexpression of interleukin-15 induces skeletal muscle hypertrophy in vitro: implications for treatment of muscle wasting disorders. Experimental cell research. 2002;280(1):55-63.

23. Seldin MM, Wong GW. Regulation of tissue crosstalk by skeletal muscle-derived myonectin and other myokines. Adipocyte. 2012;1(4):200-2. 
24. Seldin MM, Peterson JM, Byerly MS, Wei Z, Wong GW. Myonectin (CTRP15), a novel myokine that links skeletal muscle to systemic lipid homeostasis. J Biol Chem. 2012;287(15):11968-80.

25. Brandan E, Fuentes $M$, Andrade W. The proteoglycan decorin is synthesized and secreted by differentiated myotubes. Eur J Cell Biol. 1991;55(2):209-16.

26. Henningsen J, Rigbolt KT, Blagoev B, Pedersen BK, Kratchmarova I. Dynamics of the skeletal muscle secretome during myoblast differentiation. Molecular cellular proteomics: MCP. 2010;9(11):2482-96.

27. Miura T, Kishioka Y, Wakamatsu J, Hattori A, Hennebry A, Berry CJ, et al. Decorin binds myostatin and modulates its activity to muscle cells. Biochem Biophys Res Commun. 2006;340(2):675-80.

28. Guiraud S, van Wittenberghe L, Georger C, Scherman D, Kichler A. Identification of decorin derived peptides with a zinc dependent anti-myostatin activity. Neuromuscular disorders: NMD. 2012;22(12):1057-68.

29. Kanzleiter T, Rath M, Görgens SW, Jensen J, Tangen DS, Kolnes AJ, et al. The myokine decorin is regulated by contraction and involved in muscle hypertrophy. Biochem Biophys Res Commun. 2014;450(2):1089-94.

30. Marshall A, Salerno MS, Thomas M, Davies T, Berry C, Dyer K, et al. Mighty is a novel promyogenic factor in skeletal myogenesis. Experimental cell research. 2008;314(5):1013-29.

31. Mitchell CJ, Churchward-Venne TA, Bellamy L, Parise G, Baker SK, Phillips SM. Muscular and systemic correlates of resistance training-induced muscle hypertrophy. PloS one. 2013;8(10):e78636.

32. Masiero E, Agatea L, Mammucari C, Blaauw B, Loro E, Komatsu M, et al. Autophagy is required to maintain muscle mass. Cell Metabol. 2009;10(6):507-15.

33. Sandri M. Protein breakdown in muscle wasting: role of autophagy-lysosome and ubiquitinproteasome. Int J Biochem Cell Biol. 2013;45(10):2121-9.

34. Gumucio JP, Mendias CL. Atrogin-1, MuRF-1, and sarcopenia. Endocrine. 2013;43(1):12-21.

35. Mendias CL, Kayupov E, Bradley JR, Brooks SV, Claflin DR. Decreased specific force and power production of muscle fibers from myostatin-deficient mice are associated with a suppression of protein degradation. J Appl Physiol. 2011;111(1):185-91.

36. Gomes MD, Lecker SH, Jagoe RT, Navon A, Goldberg AL. Atrogin-1, a muscle-specific F-box protein highly expressed during muscle atrophy. Proc Natl Acad Sci USA. 2001;98(25):14440-5.

37. Bodine SC, Latres E, Baumhueter S, Lai VK, Nunez L, Clarke BA, et al. Identification of ubiquitin ligases required for skeletal muscle atrophy. Science. 2001;294(5547):1704-8.

38. Foletta VC, White LJ, Larsen AE, Leger B, Russell AP. The role and regulation of MAFbx/atrogin-1 and MuRF1 in skeletal muscle atrophy. Pflug Arch: Eur J Physiol. 2011;461(3):325-35.

39. Léger B, Cartoni R, Praz M, Lamon S, Dériaz O, Crettenand A, et al. Akt signalling through GSK-3ß, mTOR and Foxo1 is involved in human skeletal muscle hypertrophy and atrophy. J Physiol. 2006;576(3):923-33.

40. Coffey VG, Shield A, Canny BJ, Carey KA, Cameron-Smith D, Hawley JA. Interaction of contractile activity and training history on mRNA abundance in skeletal muscle from trained athletes. American 
journal of physiology Endocrinology metabolism. 2006;290(5):E849-55.

41. Mascher H, Tannerstedt J, Brink-Elfegoun T, Ekblom B, Gustafsson T, Blomstrand E. Repeated resistance exercise training induces different changes in mRNA expression of MAFbx and MuRF-1 in human skeletal muscle. American journal of physiology Endocrinology metabolism. 2008;294(1):E43-51.

42. Louis $E$, Raue $U$, Yang Y, Jemiolo B, Trappe S. Time course of proteolytic, cytokine, and myostatin gene expression after acute exercise in human skeletal muscle. J Appl Physiol. 2007;103(5):174451.

43. Yang $Y$, Jemiolo $B$, Trappe $S$. Proteolytic mRNA expression in response to acute resistance exercise in human single skeletal muscle fibers. J Appl Physiol. 2006;101(5):1442-50.

44. Nedergaard A, Vissing K, Overgaard K, Kjaer M, Schjerling P. Expression patterns of atrogenic and ubiquitin proteasome component genes with exercise: effect of different loading patterns and repeated exercise bouts. J Appl Physiol. 2007;103(5):1513-22.

45. Kostek MC, Chen YW, Cuthbertson DJ, Shi R, Fedele MJ, Esser KA, et al. Gene expression responses over $24 \mathrm{~h}$ to lengthening and shortening contractions in human muscle: major changes in CSRP3, MUSTN1, SIX1, and FBX032. Physiol Genom. 2007;31(1):42-52.

46. Schoenfeld BJ, Ogborn DI, Vigotsky AD, Franchi MV, Krieger JW. Hypertrophic Effects of Concentric vs. Eccentric Muscle Actions: A Systematic Review and Meta-analysis. Journal of strength conditioning research. 2017;31(9):2599-608.

47. Roig M, O'Brien K, Kirk G, Murray R, McKinnon P, Shadgan B, et al. The effects of eccentric versus concentric resistance training on muscle strength and mass in healthy adults: a systematic review with meta-analysis. Br J Sports Med. 2009;43(8):556-68.

48. Maeo S, Shan X, Otsuka S, Kanehisa H, Kawakami Y. Neuromuscular adaptations to work-matched maximal eccentric versus concentric training. Med Sci sports Exerc. 2018;50(8):1629.

49. Franchi MV, Reeves ND, Narici MV. Skeletal Muscle Remodeling in Response to Eccentric vs. Concentric Loading: Morphological, Molecular, and Metabolic Adaptations. Frontiers in physiology. 2017;8:447.

50. Farthing JP, Chilibeck PD. The effects of eccentric and concentric training at different velocities on muscle hypertrophy. European journal of applied physiology. 2003;89(6):578-86.

51. Cadore EL, Gonzalez-Izal M, Pallares JG, Rodriguez-Falces J, Hakkinen K, Kraemer WJ, et al. Muscle conduction velocity, strength, neural activity, and morphological changes after eccentric and concentric training. Scand J Med Sci Sports. 2014;24(5):e343-52.

52. Blazevich AJ, Cannavan D, Coleman DR, Horne S. Influence of concentric and eccentric resistance training on architectural adaptation in human quadriceps muscles. J Appl Physiol. 2007;103(5):1565-75.

53. Isner-Horobeti ME, Rasseneur L, Lonsdorfer-Wolf E, Dufour SP, Doutreleau S, Bouitbir J, et al. Effect of eccentric versus concentric exercise training on mitochondrial function. Muscle Nerve. 2014;50(5):803-11. 
54. van Melick N, Meddeler BM, Hoogeboom TJ, Nijhuis-van der Sanden MW, van Cingel RE. How to determine leg dominance: The agreement between self-reported and observed performance in healthy adults. PloS one. 2017;12(12):e0189876.

55. Cornachione A, Cação-Benedini LO, Martinez EZ, Neder L, Mattiello-Sverzut AC. Effects of eccentric and concentric training on capillarization and myosin heavy chain contents in rat skeletal muscles after hindlimb suspension. Acta histochemica. 2011;113(3):277-82.

56. Tortorella LL, Milasincic DJ, Pilch PF. Critical proliferation-independent window for basic fibroblast growth factor repression of myogenesis via the p42/p44 MAPK signaling pathway. J Biol Chem. 2001;276(17):13709-17.

57. Sotiropoulos A, Ohanna M, Kedzia C, Menon RK, Kopchick JJ, Kelly PA, et al. Growth hormone promotes skeletal muscle cell fusion independent of insulin-like growth factor 1 up-regulation. Proc Natl Acad Sci USA. 2006;103(19):7315-20.

58. Imaoka Y, Kawai M, Mori F, Miyata H. Effect of eccentric contraction on satellite cell activation in human vastus lateralis muscle. J Physiol Sci. 2015;65(5):461-9.

59. O'Reilly C, McKay B, Phillips S, Tarnopolsky M, Parise G. Hepatocyte growth factor (HGF) and the satellite cell response following muscle lengthening contractions in humans. Muscle Nerve: Official Journal of the American Association of Electrodiagnostic Medicine. 2008;38(5):1434-42.

60. Psilander N, Damsgaard R, Pilegaard H. Resistance exercise alters MRF and IGF-I mRNA content in human skeletal muscle. J Appl Physiol. 2003;95(3):1038-44.

61. Mozdziak PE, Greaser ML, Schultz E. Myogenin, MyoD, and myosin expression after pharmacologically and surgically induced hypertrophy. J Appl Physiol. 1998;84(4):1359-64.

62. Pourranjbar M, Arabnejad N, Naderipour K, Rafie F. Effects of Aerobic Exercises on Serum Levels of Myonectin and Insulin Resistance in Obese and Overweight Women. Journal of medicine life. 2018;11(4):381-6.

63. Seldin MM, Lei X, Tan SY, Stanson KP, Wei Z, Wong GW. Skeletal muscle-derived myonectin activates the mammalian target of rapamycin (mTOR) pathway to suppress autophagy in liver. Journal of biological chemistry. 2013;288(50):36073-82.

64. Kautz L, Jung G, Nemeth E, Ganz T. Erythroferrone contributes to recovery from anemia of inflammation. Blood The Journal of the American Society of Hematology. 2014;124(16):2569-74.

65. Kautz L, Jung G, Valore EV, Rivella S, Nemeth E, Ganz T. Identification of erythroferrone as an erythroid regulator of iron metabolism. Nat Genet. 2014;46(7):678-84.

66. Dieli-Conwright CM, Spektor TM, Rice JC, Sattler FR, Schroeder ET. Hormone therapy attenuates exercise-induced skeletal muscle damage in postmenopausal women. J Appl Physiol. 2009;107(3):853-8.

67. Bazgir B, Salesi M, Koushki M, Amirghofran Z. Effects of eccentric and concentric emphasized resistance exercise on IL-15 serum levels and its relation to inflammatory markers in athletes and non-athletes. Asian journal of sports medicine. 2015;6(3). 
68. Nielsen AR, Mounier R, Plomgaard P, Mortensen OH, Penkowa M, Speerschneider T, et al. Expression of interleukin-15 in human skeletal muscle effect of exercise and muscle fibre type composition. $J$ Physiol. 2007;584(Pt 1):305-12.

69. Quinn LS, Anderson BG, Conner JD, Wolden-Hanson T, Marcell TJ. IL-15 is required for postexercise induction of the pro-oxidative mediators PPARS and SIRT1 in male mice. Endocrinology. 2014;155(1):143-55.

70. Heinemeier KM, Bjerrum SS, Schjerling P, Kjaer M. Expression of extracellular matrix components and related growth factors in human tendon and muscle after acute exercise. Scand J Med Sci Sports. 2013;23(3):e150-61.

71. Bugera EM, Duhamel TA, Peeler JD, Cornish SM. The systemic myokine response of decorin, interleukin-6 (IL-6) and interleukin-15 (IL-15) to an acute bout of blood flow restricted exercise. European journal of applied physiology. 2018;118(12):2679-86.

72. Stefanetti RJ, Lamon S, Rahbek SK, Farup J, Zacharewicz E, Wallace MA, et al. Influence of divergent exercise contraction mode and whey protein supplementation on atrogin-1, MuRF1, and FOX01/3A in human skeletal muscle. J Appl Physiol. 2014;116(11):1491-502.

73. Fry CS, Drummond MJ, Glynn EL, Dickinson JM, Gundermann DM, Timmerman KL, et al. Skeletal muscle autophagy and protein breakdown following resistance exercise are similar in younger and older adults. The journals of gerontology Series A, Biological sciences and medical sciences. 2013;68(5):599-607.

74. Glynn EL, Fry CS, Drummond MJ, Dreyer HC, Dhanani S, Volpi E, et al. Muscle protein breakdown has a minor role in the protein anabolic response to essential amino acid and carbohydrate intake following resistance exercise. American Journal of Physiology-Regulatory Integrative Comparative Physiology. 2010;299(2):R533-R40.

75. Churchley EG, Coffey VG, Pedersen DJ, Shield A, Carey KA, Cameron-Smith D, et al. Influence of preexercise muscle glycogen content on transcriptional activity of metabolic and myogenic genes in well-trained humans. J Appl Physiol. 2007;102(4):1604-11.

\section{Figures}



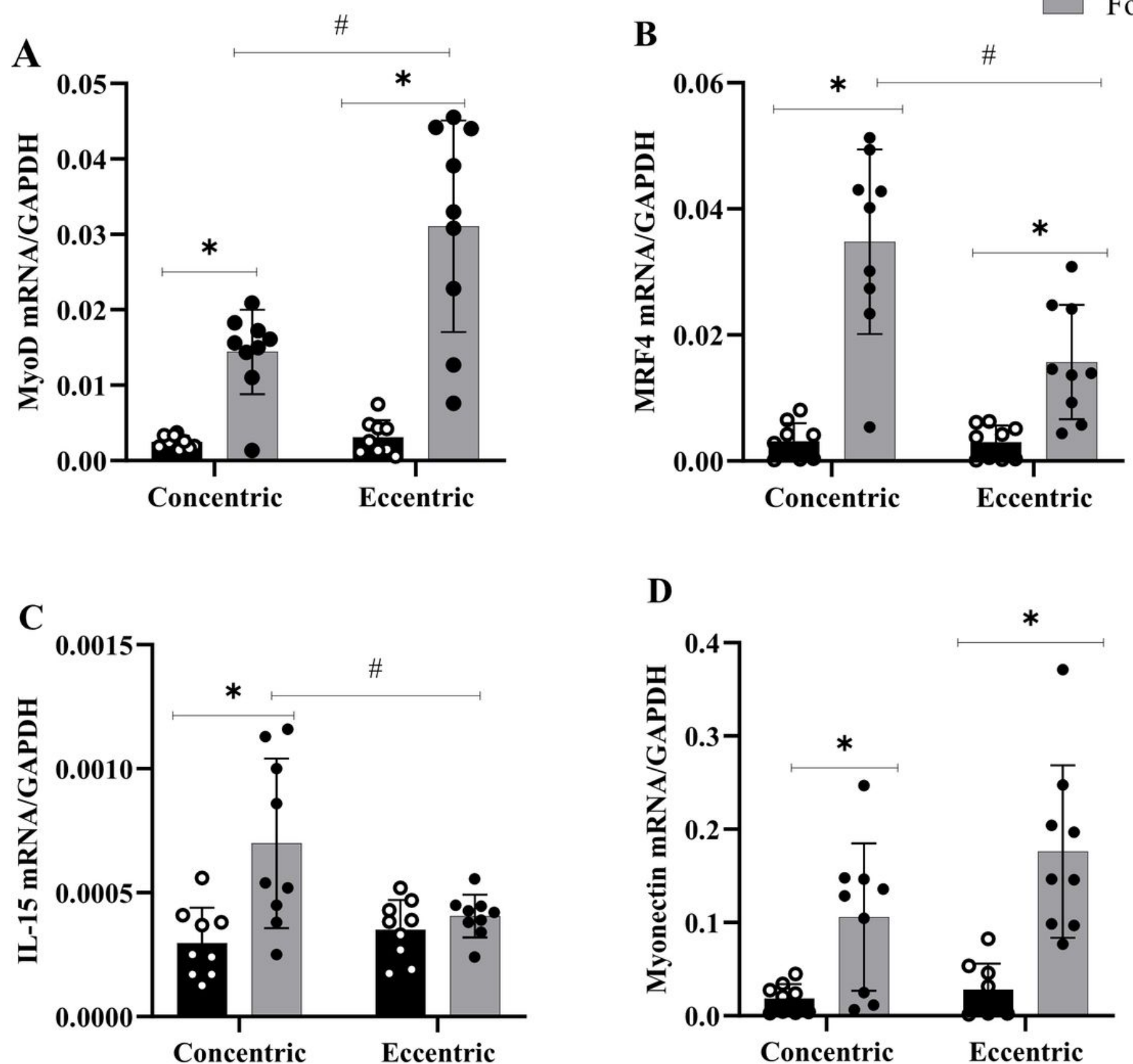

Figure 1

Gene expression of MyoD (A), MRF4 (B), IL-15 (C), and Myonectin (D) in the Vastus Lateralis muscle in response to Eccentric and Concentric contractions. The expression levels of MyoD, MRF4 and Myonectin significantly increased in both eccentric and concentric groups from baseline to follow-up $(P<0.05)$. However, IL-15 increased significantly only on concentric group $(P<0.05)$. Each value is presented as the mean $\pm S E(n=9)$. * Statistical analysis indicates the significant difference between baseline and followup: $p \leq 0.05$. $\neq$ Statistical analysis indicates the significant difference between groups at follow-up: $p$ $\leq 0.05$. 

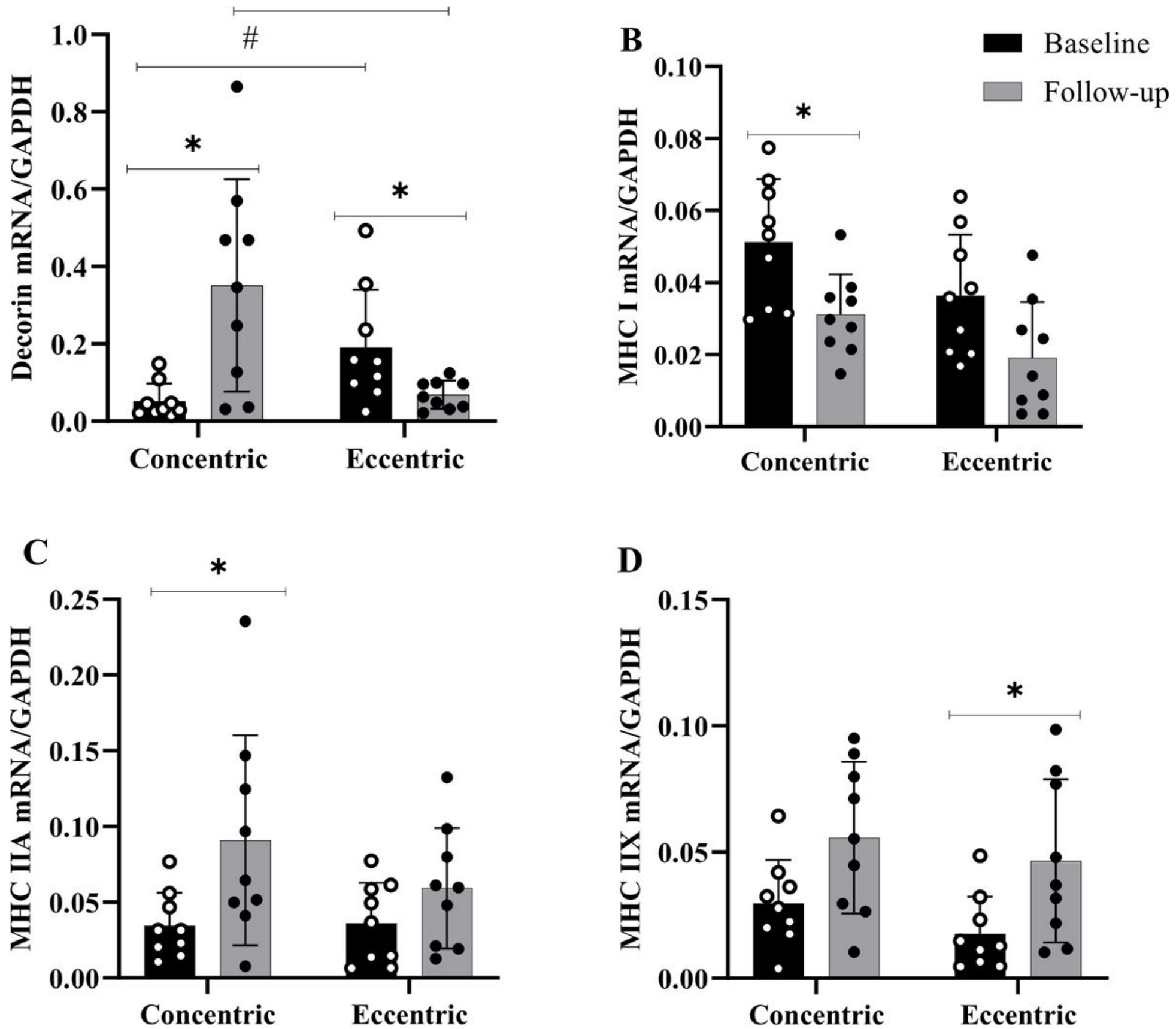

Figure 2

Effect of Eccentric and Concentric contraction on the expression levels of Decorin (A) and MHC isoforms $(B, C$, and $D)$ in Vastus Lateralis muscle. In the concentric group, the expression level of Decorin, $\mathrm{MHC}$ I and MHC IIA significantly increased on follow-up time compared to the baseline time $(P<0.05)$. The Decorin and MHC IIX expression level was significantly increased in the eccentric group on follow-up time compared to baseline $(P<0.05)$. Each value is presented as the mean $\pm S E(n=9)$. * Statistical analysis indicates the significant difference between baseline and follow-up: $p \leq 0.05$. $\neq$ Statistical analysis indicates the significant difference between groups at follow-up: $p \leq 0.05$. 

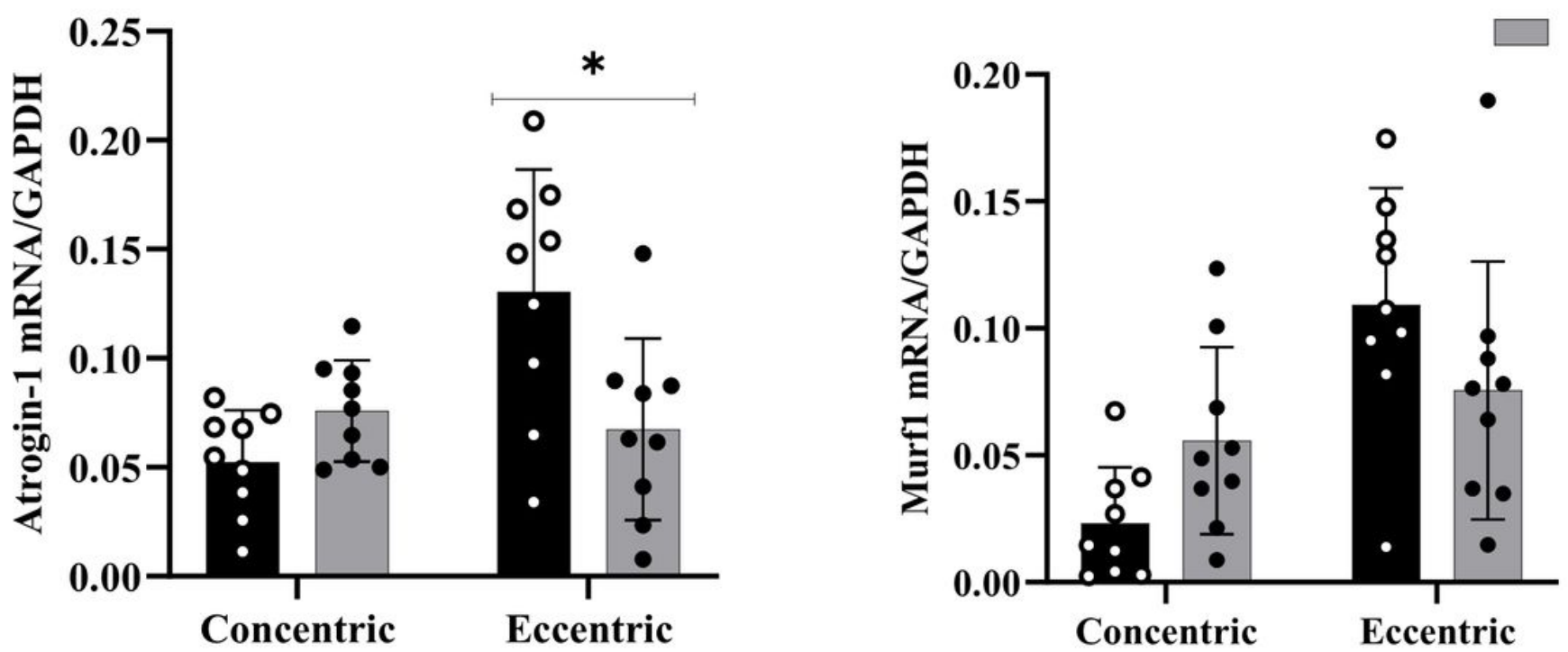

Figure 3

Gene expression of Atrogin-1 (A) and MuRF1 (B) in the Vastus Lateralis muscle in response to Eccentric and Concentric contractions. Only the Atrogin-1 expression level was significantly changed on follow-up compared to baseline in the eccentric group $(P<0.05)$. Each value is presented as the mean $\pm S E(n=9)$. * Statistical analysis indicates the significant difference between baseline and follow-up: $p \leq 0.05$. 